\title{
Efeito do Condicionamento Osmótico de Sementes de SoJa sobre a Habilidade Competitiva da Cultura com as Plantas daninhas ${ }^{1}$
}

\author{
Soybean Seed Osmoconditioning Effect on the Crop Competitive Ability against Weeds
}

\author{
NUNES, U.R. ${ }^{2}$, SILVA, A.A. ${ }^{3}$, REIS, M.S. ${ }^{4}$, SEDIYAMA, C.S. ${ }^{5}$ e SEDIYAMA, T. ${ }^{5}$
}

\begin{abstract}
RESUMO - Este trabalho teve como objetivo avaliar os efeitos do condicionamento osmótico de sementes de soja sobre o desempenho da cultura e sua habilidade competitiva com as plantas daninhas. As sementes de soja, da variedade UFV 16, colhidas nos estádios fenológicos R8 e $\mathrm{R} 8$ + 15 dias, foram submetidas ao condicionamento osmótico em solução de polietileno glicol (PEG 6000), a -0,8 MPa e $20^{\circ} \mathrm{C}$, por 96 horas. Como testemunha foram utilizadas sementes sem tratamento de pré-embebição, colhidas nos mesmos estádios fenológicos. Em laboratório, a germinação e o vigor das sementes foram avaliados pelo teste-padrão de germinação, utilizando-se o delineamento inteiramente casualizado, no esquema fatorial $2 \times 2$, com quatro repetições. A campo foram realizados dois experimentos, utilizando sementes com e sem condicionamento osmótico, colhidas também nos estádios fenológicos R8 e R8+15, respectivamente. Em ambos os experimentos, utilizando o delineamento de blocos casualizados com quatro repetições, foram avaliados os efeitos de diferentes períodos $(0,15,30,45,60$ e 125 dias após a emergência da soja) de convivência da soja com as plantas daninhas. Os maiores valores de germinação e vigor, de estande inicial e final e de rendimento de grãos foram observados nos tratamentos com as sementes condicionadas e colhidas no estádio fenológico R8. As demais características agronômicas avaliadas (altura de plantas, número de nós, número de vagens por planta, número de sementes por planta, número de sementes por vagem e peso de 100 sementes) não foram alteradas pelo condicionamento. $O$ efeito competitivo cultura-planta daninha foi verificado pelos menores valores de biomassa seca de plantas daninhas, nos tratamentos em que foram utilizadas as sementes colhidas no estádio R8 e condicionadas osmoticamente.
\end{abstract}

Palavras-chave: polietileno glicol, germinação, vigor, biomassa seca.

\begin{abstract}
This work aimed to evaluate the effects of the osmotic conditioning of soybean seeds on its performance and competitive ability against weeds. Soybean seeds, variety UFV 16, were harvested at the phenological stages $R 8$ and $R 8+15$ days and submitted to osmotic conditioning in a polyethylene glycol (PEG 6000) solution, at $-0.8 \mathrm{Mpa}$, and $20^{\circ} \mathrm{C}$, for 96 hours. Seeds without pre-hydration treatment harvested at the same phenological stage were used as control. Seed germination and vigor were analyzed under laboratory conditions through the standard germination test, using a randomized complete design, $2 \times 2$ factorial, with 4 repetitions. Two experiments were conducted under field conditions, using seeds with and without osmotic conditioning, also harvested at the phenological stages $R 8$ and $R 8+15$ days, respectively. In both the experiments using randomized blocks with four repetitions, the effects of different weed coexistence periods $(0,15$, 30, 45, 60 and 125 days after soybean emergence) with the soybean crop were evaluated. The highest germination and vigor values related to initial and final stands and to grain yield were found in the treatments of seeds conditioned and harvested at the phenological stage R8. Other characteristics evaluated (plant height, number of nodes, number of pods per plant, number of seeds per plant, number of seeds per pod and 100-seed weight) were not altered by conditioning. The competitive effect between weed and crop was verified by the lowest dry biomass values of the weeds, in the treatments in which seeds were harvested at the phenological stage R8 and were osmotically conditioned.
\end{abstract}

Key words: Polyethylene-glycol, germination, vigor, dry biomass.

Recebido para publicação em 10.12.2001 e na forma revisada em 2.4.2003.

2 Eng.-Agr., D.S., Prof. Adjunto, Faculdades Federais Integradas de Diamantina, 39100-000 Diamantina-MG. ${ }^{3}$ Eng.-Agr., D.S., Prof. Adjunto, Dep. de Fitotecnia da Universidade Federal de Viçosa - UFV, Bolsista do CNPq, 36571-000 Viçosa-MG; ${ }^{4}$ Eng.-Agr., D.S., Prof. Titular, Dep. de Fitotecnia da UFV, Bolsista do CNPq; ${ }^{5}$ Eng.-Agr., Ph.D., Prof. Titular, Dep. de Fitotecnia da UFV, Bolsista do CNPq.

Planta Daninha, Viçosa-MG, v.20, n.1, p.27-35, 2002 


\section{INTRODUÇÃO}

Um dos fatores básicos para se obter elevada produtividade de soja é o adequado estabelecimento da cultura a campo. Técnicas que reduzem o tempo de exposição das sementes durante a fase inicial de plantio podem aumentar a tolerância às condições adversas, favorecendo o estabelecimento rápido e uniforme da cultura. Dentre os diversos procedimentos estudados, o condicionamento osmótico de sementes, também conhecido como "priming", tem-se mostrado promissor para grande número de espécies (Braccini, 1996; Del Giúdice, 1996; Camargo, 1998; Lima, 1999). Na cultura da soja, essa técnica possibilitou melhoria na emergência e promoveu estabelecimento mais rápido e uniforme de plântulas em campo (Helsel et al., 1986). O condicionamento osmótico consiste em colocar as sementes em contato com solução inerte, mas com atividade osmótica, como o polietileno glicol (PEG 6000). Esta técnica permite a ocorrência dos processos preparatórios da germinação, impedindo a emissão da raiz primária, mesmo após semanas de contato entre a semente e a solução osmótica (Heydecker et al., 1975).

Durante o condicionamento osmótico a taxa e o volume de água absorvida são reduzidos, e a semente se hidrata lentamente, o que permite maior tempo para a reparação ou reorganização das membranas. Possibilita, também, que os tecidos se desenvolvam de forma mais ordenada, reduzindo a incidência de injúrias ao embrião provocadas pela rápida embebição. Mudanças fisiológicas ocorrem nas sementes, como o aumento do poder germinativo e do vigor, a tolerância às condições de estresse, a redução do vazamento de solutos e de injúrias por embebição rápida e a superação da dormência (Khan, 1992).

$\mathrm{O}$ aparente aumento do vigor das sementes pode ser explicado pela retenção de preparados fisiológicos durante o período do condicionamento osmótico, o que revigora a semente para germinação e melhora o seu desempenho em campo (Khan, 1992). No entanto, as sementes apresentarão germinação precoce e sincronizada, o que resulta em estabelecimento uniforme de plântulas, proporcionando cobertura do solo mais rápida (Heydecker et al., 1975). Conseqüentemente, a cultura terá maior capacidade na competição com as plantas daninhas (Radosevich et al., 1996). Esse fato é altamente desejável no manejo de plantas daninhas, quando se objetiva explorar a máxima interferência da cultura e da competição culturaplanta daninha, visando reduzir as perdas e os gastos com herbicidas, além de reduzir a contaminação ambiental pelos agrotóxicos.

Pesquisas envolvendo o condicionamento osmótico de sementes de soja confirmam a eficiência dessa técnica em aumentar a porcentagem de emergência e favorecer o estabelecimento mais rápido e uniforme das plântulas nos testes realizados em laboratório e em casa de vegetação (Braccini, 1996; Braccini et al., 1997; Del Giúdice et al., 1999). Entretanto, o efeito dessa técnica na emergência de plântulas e no desempenho das plantas no campo, submetidas à pressão de plantas daninhas, não tem sido pesquisado, o que motivou a realização deste trabalho.

\section{MATERIAL E MÉTODOS}

Utilizaram-se para este trabalho sementes de soja, variedade UFV-16 (Capinópolis), produzidas no ano agrícola 1997/98. A colheita foi realizada no estádio fenológico R8 (quando 95\% das vagens apresentavam a coloração típica da vagem madura) e 15 dias após este estádio. Após limpeza e secagem, em condições naturais até obter teores de umidade entre 10 e $11 \%$ (base úmida), as sementes foram acondicionadas em sacos de tecido de algodão e mantidas a $10^{\circ} \mathrm{C}$ e $70 \%$ de umidade relativa do ar, até o início dos experimentos (7.12.1998). Naquela ocasião, as sementes foram submetidas à técnica do condicionamento osmótico com solução de polietileno glicol (PEG 6000), de acordo com a metodologia adaptada de Del Giúdice (1996) e Braccini (1996). Como controle, foram utilizadas sementes sem condicionamento osmótico, colhidas nos estádios fenológicos R8 e R8 + 15 dias.

Para realização do condicionamento osmótico, foram utilizados $1,0 \mathrm{~kg}$ de sementes e 2,0 L de solução de PEG 6000, colocados em bandeja plástica de $42 \times 28 \times 10 \mathrm{~cm}$, sobre quatro folhas de papel germitest, cortadas na dimensão da caixa. As sementes foram umedecidas, seguindo a proporção de 100 sementes para cada $30 \mathrm{~mL}$ da solução de PEG 6.000 + $0,2 \%$ do fungicida Thiram, com potencial 
osmótico ajustado a -0,8 MPa. Em cada bandeja, foi instalado um aerador de aquário, adaptado, visando promover a aeração da solução de PEG 6000. As bandejas foram colocadas em estufa incubadora BOD, regulada à temperatura de $20^{\circ} \mathrm{C}$, por 96 horas. A concentração de PEG 6000 utilizada para obter o potencial osmótico desejado (-0,8 $\mathrm{MPa})$, à temperatura de $20^{\circ} \mathrm{C}$, foi de $251,028 \mathrm{~g} \mathrm{~L}$ de água desmineralizada, de acordo com a equação proposta por Michel \& Kaufmann (1973). Logo após o período de condicionamento osmótico, as sementes foram lavadas superficialmente com água de torneira, por dois minutos, com a finalidade de eliminar o excesso de PEG, e secadas, superficialmente, com papel germitest.

Amostras das sementes com e sem condicionamento osmótico foram, em seguida, submetidas ao teste de germinação, para avaliação da qualidade fisiológica. Utilizaram-se quatro repetições de 50 sementes, distribuídas entre três folhas de papel-toalha, umedecidas com água desmineralizada, as quais foram colocadas em germinador a $25{ }^{\circ} \mathrm{C}$. As avaliações foram realizadas aos cinco (primeira contagem) e aos oito dias (contagem final), registrando-se o número de plântulas normais, segundo os critérios estabelecidos pelas Regras de Análise de Sementes (Brasil, 1992).

Os experimentos em campo foram instalados em área do Departamento de Fitotecnia da UFV. Logo depois do preparo convencional do solo, sementes de Brachiaria decumbens foram semeadas a lanço na densidade de 200 sementes $\mathrm{m}^{2}$. Seis dias após a semeadura fez-se o plantio da soja (11.12.1988). Cada parcela foi constituída de cinco fileiras de $5,0 \mathrm{~m}$ de comprimento, espaçadas entre si de 0,4 m. Foram consideradas como área útil as três fileiras centrais, descartando-se $0,5 \mathrm{~m}$ das extremidades por ocasião da colheita. Dois experimentos foram instalados, um ao lado do outro, no mesmo tipo de solo (Argissolo argiloso) e no mesmo dia. No primeiro, foram usadas sementes colhidas no estádio fenológico R8 e, no segundo, sementes colhidas no estádio fenológico R8 +15 dias, com ou sem condicionamento osmótico. A semeadura foi feita manualmente, na densidade de 20 sementes por metrolinear.

Os tratamentos foram dispostos no campo de tal forma que a cultura convivesse com as plantas daninhas por períodos crescentes de competição $(0,15,30,45$ e 60 dias após a emergência das plantas de soja). Após esses períodos, as plantas daninhas presentes nas parcelas foram eliminadas com enxada, entre as fileiras, e manualmente, dentro das fileiras, impedindo-se o desenvolvimento até a colheita.

No momento anterior às capinas foram feitas avaliações das plantas daninhas (número e biomassa seca por espécie) em $10 \%$ da área útil, considerando três pontos ao acaso por parcela. Foram utilizadas parcelas testemunhas, sempre com competição com as plantas daninhas até a colheita ( 125 dias). A biomassa seca das plantas daninhas (parte aérea) foi determinada após a secagem destas em estufa a $75^{\circ} \mathrm{C}$, até atingirem peso constante. Além das plantas daninhas, foram avaliadas também as seguintes características: estandes inicial e final da soja, altura das plantas, número de nós, número de vagens por planta, número de sementes por vagem, número de sementes por planta, peso de 100 sementes e produtividade.

O delineamento experimental utilizado para determinação do vigor e da germinação, no laboratório, foi o inteiramente casualizado, com quatro repetições, no esquema fatorial $2 \times 2$, correspondendo, respectivamente, aos fatores condicionamento osmótico de sementes (com e sem condicionamento) e época de colheita de sementes (R8 e R8 + 15 dias). Nos experimentos conduzidos em campo utilizou-se o delineamento em blocos casualizados, no esquema de parcelas subdivididas, com quatro repetições. Em ambos os experimentos, as sementes condicionadas e não-condicionadas foram colocadas nas parcelas e, nas subparcelas, os períodos de competição da soja com plantas daninhas.

Os dados das características avaliadas nos dois experimentos foram analisados em conjunto, de forma que o condicionamento osmótico de sementes foi considerado como tratamento primário, e os períodos de competição com plantas daninhas, como tratamento secundário.

Os valores da porcentagem de plântulas normais obtidos no teste de germinação foram previamente transformados em arco-seno $\sqrt{\% / 100}$, para análise estatística, tendo as médias sido destransformadas, para apresentação.

Planta Daninha, Viçosa-MG, v.20, n.1, p.27-35, 2002 
Os resultados foram submetidos às análises de variância e de regressão, sendo as médias comparadas pelo teste $\mathrm{F}$ a $5 \%$ de probabilidade. Os modelos foram escolhidos por meio da significância dos coeficientes de regressão, utilizando o teste $\mathrm{t}$ a 1 e $5 \%$ de probabilidade, e pelo coeficiente de determinação.

\section{RESULTADOS E DISCUSSÃO}

Observa-se na Tabela 1 que, tanto para vigor como para germinação, a embebição das sementes em PEG 6000 proporcionou aumento significativo em relação às testemunhas sem condicionamento osmótico. Quanto à época de colheita, constatou-se que as sementes colhidas no estádio R8 de maturação superaram, na média dos resultados, as sementes colhidas no estádio R8 + 15 dias, nas duas características avaliadas. Esses efeitos benéficos do condicionamento osmótico em sementes de soja, na germinação e no vigor, também foram observados por Braccini et al. (1997) e Del Giúdice et al. (1999).

Quando a semente é colocada em contato com a água, a embebição ocorre rapidamente, o que pode lhe causar danos. Com a rápida embebição ocorre a redução na integridade das membranas, com perda de constituintes celulares e baixa germinação. Quando as sementes são submetidas ao condicionamento osmótico, reduzem-se a taxa e o volume de água absorvida pelo agente osmótico e a semente embebe de forma lenta, o que permite reestruturar as membranas e a possibilidade de os tecidos celulares se desenvolverem mais ordenadamente (Khan, 1992).

Nos experimentos em campo, as plantas daninhas que ocorreram na área experimental foram a tiririca (Cyperus rotundus), a braquiária (Brachiaria decumbens), o nabo (Raphanus raphanistrum), o leiteiro (Euphorbia heterophylla), a azedinha (Oxalis latifolia), o picão-preto (Bidens pilosa) e a corda-de-viola (Ipomoea purpurea).

A azedinha, o picão-preto e a corda-de-viola ocorreram em número reduzido nas parcelas do experimento. Estas, além do nabo e do leiteiro, tiveram redução na densidade de plantas ao longo do ciclo da cultura e dos períodos de competição, devido principalmente à competição exercida pelas plantas de braquiária, tiririca e da própria cultura. A densidade média geral de plantas daninhas foi em torno de 284 plantas nî, com variação máxima de 234 a 328 plantas $\mathrm{m}^{2}$, sendo a maior parte representada pela braquiária e pela tiririca. Estas duas espécies não alteraram suas densidades com os diferentes períodos de competição e representaram cerca de $90 \%$ das plantas daninhas coletadas, em média, o que indica uniformidade nas duas áreas do experimento.

A análise de variância dos dados indicou a existência de interação significativa apenas para estande final e número de sementes por planta. Para essas variáveis, ocorreu interação entre época de colheita e períodos de competição com plantas daninhas. Nas características restantes, foram analisados apenas os efeitos

Tabela 1 - Médias estimadas, em porcentagem de plântulas normais, na primeira contagem e contagem final do teste de germinação de sementes de soja, variedade UFV-16, submetidas ou não ao condicionamento osmótico, em duas épocas de colheita $^{1 /}$

\begin{tabular}{|c|c|c|c|c|c|c|}
\hline \multirow{3}{*}{ Condicionamento osmótico } & \multicolumn{3}{|c|}{ Primeira contagem } & \multicolumn{3}{|c|}{ Contagem final } \\
\hline & \multicolumn{2}{|c|}{ Época de Colheita } & \multirow{2}{*}{ Média } & \multicolumn{2}{|c|}{ Época de Colheita } & \multirow{2}{*}{ Média } \\
\hline & $\mathrm{R} 8$ & $\mathrm{R} 8+15$ & & $\mathrm{R} 8$ & $\mathrm{R} 8+15$ & \\
\hline Com condicionamento & 87,14 & 80,66 & $84,02 \mathrm{a}$ & 88,14 & 82,75 & $85,55 \mathrm{a}$ \\
\hline Sem condicionamento & 82,03 & 75,26 & $78,73 \mathrm{~b}$ & 82,03 & 76,27 & $79,21 \mathrm{~b}$ \\
\hline Média & $84,66 \mathrm{~A}$ & $78,01 \mathrm{~B}$ & & $85,21 \mathrm{~A}$ & $79,59 \mathrm{~B}$ & \\
\hline CV (\%) & 3,53 & & & 3,97 & & \\
\hline
\end{tabular}

1/ Dados transformados em arco-seno $\sqrt{\% / 100}$ para análise estatística; para sua apresentação, as médias foram destransformadas.

Os valores seguidos das mesmas letras maiúsculas na horizontal e minúsculas na vertical não diferem estatisticamente pelo teste $\mathrm{F}$ a $5 \%$ de probabilidade. 
gerais, ou seja, os efeitos do condicionamento osmótico de sementes, da época de colheita e dos períodos de competição com plantas daninhas.

Na Tabela 2 estão os resultados para estande inicial, estande final, altura e número de nós de plantas de soja, resultantes de sementes submetidas ou não ao condicionamento osmótico e épocas de colheita das sementes utilizadas na semeadura. Observa-se que, quando realizado o condicionamento osmótico de sementes, os estandes inicial e final de plantas foram, em média, superiores àqueles em que não se utilizou o condicionamento osmótico. Os resultados desse efeito positivo no estande estão relacionados com os obtidos no teste de germinação (Tabela 1), em que também foi constatada melhoria no vigor e na germinação das sementes logo após os tratamentos de embebição com PEG 6000, em relação à testemunha sem tratamento osmótico. Nas condições favoráveis de temperatura e umidade no teste de germinação, as sementes osmocondicionadas superaram, na média, a testemunha em 5,29 e 6,41 pontos percentuais para vigor e germinação, respectivamente. Em campo, esse efeito na emergência das plântulas foi mais evidente, sendo a diferença no estande favorável às parcelas semeadas com sementes condicionadas osmoticamente. Para estandes inicial e final, os valores foram de 8,20 e 7,58 pontos percentuais, respectivamente, superiores em relação aos estandes de plantas resultantes de sementes sem condicionamento osmótico (Tabela 2).

Os estandes inicial e final de plantas também foram influenciados pela época de colheita das sementes, conforme pode ser observado na Tabela 2 .

A melhoria da germinação e do vigor de sementes submetidas ao condicionamento osmótico tem sido constatada em diversas culturas, em condições ambientais menos favoráveis à germinação (Bradford, 1986; Helsel et al., 1986; Braccini et al., 1999).

Segundo Bray (1995), a síntese de proteínas no condicionamento osmótico de sementes é menor que a síntese proporcionada pelas sementes embebidas em água, por igual período. No entanto, quando a germinação se processa pela eliminação do obstáculo hídrico, ocorre elevada capacidade de síntese protéica nas sementes condicionadas, sendo essa maior capacidade uma das razões pelas quais as sementes condicionadas podem suportar condições adversas.

Os dados de biomassa seca das plantas daninhas amostradas no experimento, avaliada após cada período de competição com a soja, estão ilustrados na Figura 1. Observa-se que a biomassa de braquiária teve seus valores acrescidos com o decorrer do ciclo da cultura e os períodos de competição. Nos primeiros 60 dias de desenvolvimento da soja, a biomassa de braquiária apresentou valores semelhantes nas parcelas em que as sementes foram condicionadas osmoticamente ou não, utilizando-se sementes colhidas nos estádios fenológicos R8 e R8+15. A diferença marcante foi observada apenas no final do ciclo da soja, período em que também foi constatado maior crescimento da planta daninha, tendo o acúmulo de biomassa seca sido maior nas parcelas em que não foram utilizadas sementes condicionadas, ou seja, nas parcelas com menor população final de plantas de soja, o que, conseqüentemente, proporcionou menor competição entre cultura e plantas daninhas.

A biomassa de tiririca apresentou valores consideráveis já a partir dos primeiros 15 dias de convivência com a soja, não tendo sido

Tabela 2 - Médias estimadas do estande inicial (EI) e estande final $(\mathrm{EF})$, em porcentagem do número de plantas, da altura de plantas (AP), em centímetros, do número de nós por planta $(\mathrm{NN})$ da soja, para os tratamentos sementes com e sem condicionamento osmótico e épocas de colheita das sementes utilizadas no plantio $^{\underline{1}}$

\begin{tabular}{|l|c|c|c|c|}
\hline \multirow{2}{*}{$\begin{array}{c}\text { Condicionamento } \\
\text { osmótico }\end{array}$} & \multicolumn{4}{|c|}{ Variáveis } \\
\cline { 2 - 5 } & $\mathrm{EI}$ & $\mathrm{EF}$ & $\mathrm{AP}$ & $\mathrm{NN}$ \\
\hline Com condicionamento & $61,22 \mathrm{a}$ & $61,52 \mathrm{a}$ & $82,65 \mathrm{a}$ & $13,61 \mathrm{a}$ \\
Sem condicionamento & $53,02 \mathrm{~b}$ & $53,94 \mathrm{~b}$ & $81,71 \mathrm{a}$ & $13,23 \mathrm{a}$ \\
Média & 57,12 & 57,73 & 82,18 & 13,42 \\
CV (\%) & 8,46 & 8,30 & 9,71 & 6,73 \\
\hline \multirow{2}{*}{ Época de Colheita } & \multicolumn{4}{|c|}{ Variáveis } \\
\cline { 2 - 5 } & $\mathrm{EI}$ & $\mathrm{EF}$ & $\mathrm{AP}$ & $\mathrm{NN}$ \\
\hline Estádio R8 & $63,20 \mathrm{a}$ & $64,70 \mathrm{a}$ & $81,86 \mathrm{a}$ & $13,47 \mathrm{a}$ \\
Estádio R8+15 dias & $51,05 \mathrm{~b}$ & $50,77 \mathrm{~b}$ & $82,50 \mathrm{a}$ & $13,37 \mathrm{a}$ \\
Média & 57,12 & 57,73 & 82,18 & 13,42 \\
CV (\%) & 8,46 & 8,30 & 9,71 & 6,73 \\
\hline
\end{tabular}

1/ Os valores seguidos das mesmas letras na vertical não diferem estatisticamente pelo teste $\mathrm{F}$ a $5 \%$ de probabilidade.

Planta Daninha, Viçosa-MG, v.20, n.1, p.27-35, 2002 
observadas diferenças entre os tratamentos nesse período inicial. Constatou-se na área experimental, no momento da semeadura da soja, a presença de inúmeros tubérculos de tiririca, muitos deles já apresentando o início de germinação. Esse fato, somado à agressividade competitiva e à ocorrência de elevada infestação, explica o rápido desenvolvimento dessa invasora.

Nos demais períodos de competição, as parcelas semeadas com sementes sem condicionamento osmótico e colhidas no estádio $\mathrm{R} 8$ + 15 dias apresentaram maiores valores de biomassa da invasora, quando comparadas às de outros tratamentos. Nessas parcelas, semeadas com sementes sem condicionamento osmótico, a menor população de plantas (Tabela 2), quando comparada com a dos demais tratamentos, permitiu menor sombreamento pela cultura e, possivelmente, diminuiu a competição com a invasora.
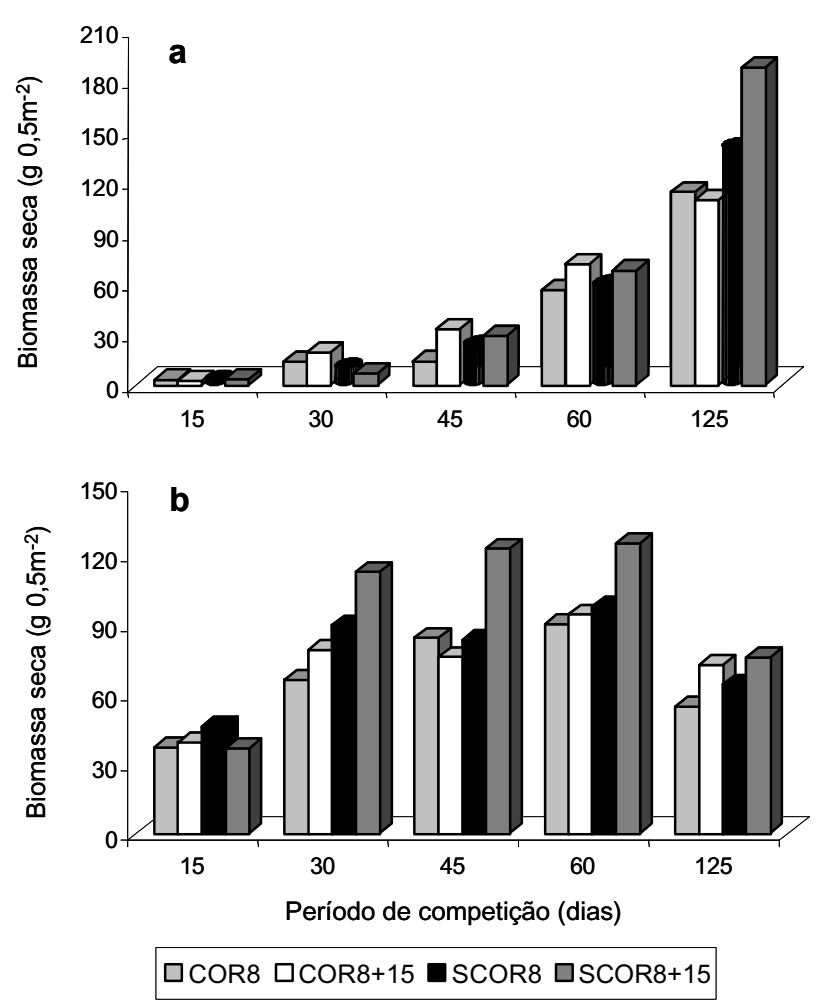

Figura 1 - Biomassa seca de braquiária (a) e tiririca (b) sob diferentes períodos de competição com a soja, com condicionamento osmótico de sementes (CO) e sem condicionamento osmótico (SCO), colhidas nos estádios $\mathrm{R} 8$ e $\mathrm{R} 8+15$ dias.
Na Figura 2 observa-se que, para os dois lotes de sementes, ocorreu decréscimo no estande final de plantas com o decorrer do ciclo da cultura e à medida que aumentou o período de competição com as plantas daninhas, observando-se, também, redução mais acentuada no estande final nas parcelas em que foram semeadas as sementes do lote de menor qualidade fisiológica $(\mathrm{R} 8+15)$.

Os resultados obtidos para altura de plantas e número de nós por planta não evidenciaram diferenças entre os tratamentos semeados com condicionamento osmótico e a testemunha e, também, as sementes colhidas nos estádios R8 e R8 + 15 dias (Tabela 2).

O efeito de competição das plantas daninhas sobre a altura de plantas de soja pode ser visualizado na Figura 3. Até 30 dias de competição a altura foi negativamente relacionada ao período de competição. A partir

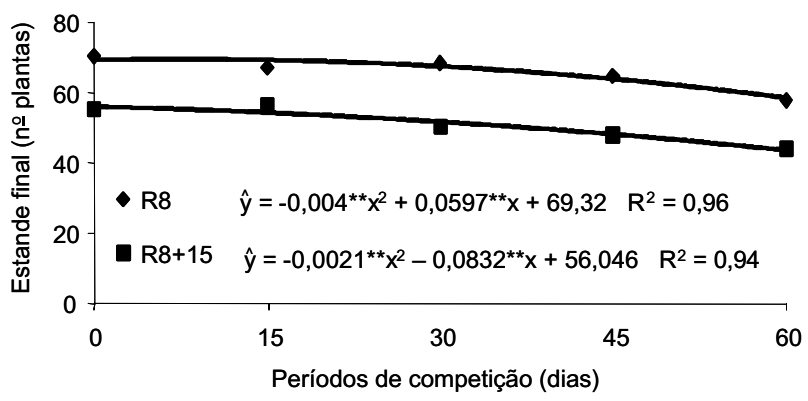

** Significativo a $1 \%$ de probabilidade pelo teste " $\mathrm{t}$ ".

Figura 2 - Estimativa do estande final de plantas de soja submetidas à competição de plantas daninhas, em duas épocas de colheita das sementes utilizadas na semeadura.

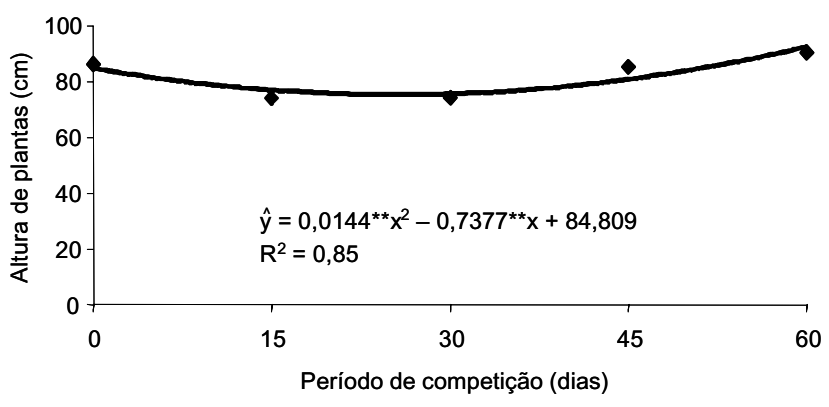

** Significativo a $1 \%$ de probabilidade pelo teste "t".

Figura 3 - Estimativa da altura de plantas de soja submetidas ou não ao condicionamento osmótico de sementes e em função de períodos de competição da cultura com plantas daninhas. 
desse período, a altura de plantas apresentou valores positivos até os 60 dias de competição. Segundo Durigan et al. (1983), essa relação positiva entre período de competição de plantas daninhas e altura de plantas de soja, por períodos acima de 30 dias, ocorre em virtude da procura por luz, o que promove o estiolamento de plantas.

Para os componentes de produção número de vagens por planta, número de sementes por planta, número de sementes/vagem e peso de 100 sementes, não houve diferença significativa entre os tratamentos de sementes com ou sem condicionamento osmótico (Tabela 3 ). Todavia, as variáveis número de vagens por planta e número de sementes por planta evidenciaram valores superiores quando foram utilizadas sementes colhidas no estádio R8, em relação a $R 8+15$. Para número de sementes/ vagem e peso de 100 sementes, não foi observada diferença significativa entre esses dois tratamentos (Tabela 3).

Os efeitos da competição das plantas daninhas sobre o número de vagens por planta, número de sementes por planta, número de sementes/vagem e peso de 100 sementes podem ser visualizados na Figura 4. Constata-se que, para cada variável, ocorreram alterações conforme os períodos de competição a que as plantas foram submetidas, porém, de modo geral, esses valores foram decrescentes à medida que o número de dias de competição da cultura com as plantas daninhas aumentou. Esses resultados estão de acordo com os verificados por Durigan et al. (1983), que obtiveram valores decrescentes para as características número de vagens por planta, número de grãos por vagem e peso de 100 grãos com o aumento do número de dias de competição com as plantas daninhas.

O condicionamento osmótico proporcionou resultados superiores para produtividade, quando comparado ao tratamento sem condicionamento, e com a utilização de sementes colhidas no estádio R8 (Tabela 3). A diferença em produtividade está relacionada ao maior número de plantas de soja que foram estabelecidas na área da parcela, isto é, nas parcelas com maior população de plantas, resultantes de sementes condicionadas e colhidas no estádio R8 (Tabela 2), foram obtidas maiores produtividades que nas parcelas onde não foram utilizados os referidos tratamentos. Esses resultados corroboram os obtidos por Helsel et al. (1986), os quais verificaram que a produção de soja foi significativamente superior com o condicionamento osmótico de sementes, na média de dois anos de experimento. O tratamento de sementes com a solução de polietileno glicol (PEG), no presente trabalho, ofereceu possibilidades de melhoria na emergência das

Tabela 3 - Médias estimadas de número de vagens por planta (NV), número de sementes por planta (NS), número de sementes por vagem (NSV), peso de 100 sementes (P100), em gramas, e produtividade (P), em kg/ha, da soja, para os tratamentos sementes com e sem condicionamento osmótico e épocas de colheita das sementes utilizadas no plantio ${ }^{1 /}$

\begin{tabular}{|c|c|c|c|c|c|}
\hline \multirow{2}{*}{ Condicionamento Osmótico } & \multicolumn{5}{|c|}{ Variáveis } \\
\hline & NV & NS & NSV & P100 & $\mathrm{P}$ \\
\hline Com condicionamento & $42,25 \mathrm{a}$ & $67,18 \mathrm{a}$ & $1,59 \mathrm{a}$ & $17,74 \mathrm{a}$ & $2.437 \mathrm{a}$ \\
\hline Sem condicionamento & $41,35 \mathrm{a}$ & $61,98 \mathrm{a}$ & 1,49 a & $17,88 \mathrm{a}$ & $2.083 \mathrm{~b}$ \\
\hline Média & 41,80 & 64,58 & $1,54 \mathrm{a}$ & 17,81 & 2.260 \\
\hline $\mathrm{CV}(\%)$ & 21,21 & 23,01 & 16,22 & 5,22 & 16,80 \\
\hline \multirow{2}{*}{ Época de Colheita } & \multicolumn{5}{|c|}{ Variáveis } \\
\hline & NV & NS & NSV & $\mathrm{P} 100$ & $\mathrm{P}$ \\
\hline Estádio R8 & $43,23 \mathrm{a}$ & $68,91 \mathrm{a}$ & $1,59 \mathrm{a}$ & $17,64 \mathrm{a}$ & $2.416 \mathrm{a}$ \\
\hline Estádio R8+15 & $40,37 \mathrm{~b}$ & $60,26 \mathrm{~b}$ & $1,49 \mathrm{a}$ & $17,98 \mathrm{a}$ & $2.104 \mathrm{~b}$ \\
\hline Média & 41,80 & 64,58 & 1,54 & 17,81 & 2.260 \\
\hline $\mathrm{CV}(\%)$ & 21,21 & 23,01 & 16,22 & 5,22 & 16,80 \\
\hline
\end{tabular}

1/ Os valores seguidos das mesmas letras na vertical não diferem estatisticamente pelo teste $\mathrm{F}$ a $5 \%$ de probabilidade. 

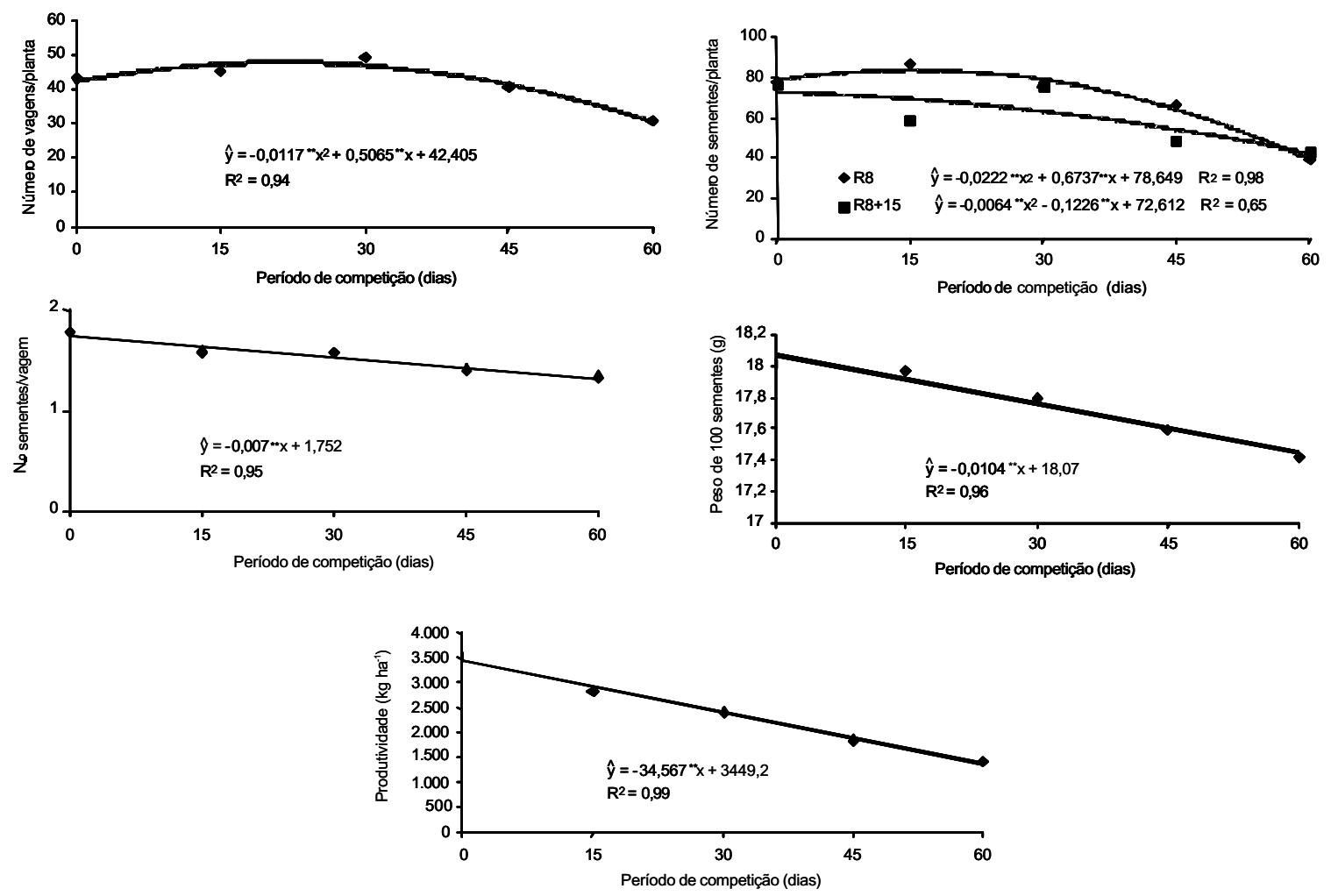

** Significativo a $1 \%$ de probabilidade pelo teste " $\mathrm{t}$ ".

Figura 4 - Estimativa de número de vagens por planta, número de sementes por planta em duas épocas de colheita de sementes, número de sementes por vagem, peso de 100 sementes e produtividade de sementes de soja submetidas ou não ao condicionamento osmótico de sementes, em função de períodos de competição da cultura com plantas daninhas.

plântulas, proporcionando melhor e mais rápido estabelecimento e, conseqüentemente, o desenvolvimento das plantas, com reflexos na produtividade da cultura, quando comparado àquele de sementes não-tratadas.

Quanto ao efeito das plantas daninhas, verificou-se que a produtividade da soja decresceu à medida que aumentou o número de dias de competição entre estas e a cultura (Figura 4). Esses resultados confirmam a redução na produtividade de grãos e sementes de soja decorrente da competição com plantas daninhas, reportada em alguns trabalhos de pesquisa (Durigan et al., 1983; Spadotto et al., 1992; Fleck, 1996).

\section{LITERATURA CITADA}

BRACCINI, A. L. Relação entre potencial hídrico, condicionamento osmótico e qualidade fisiológica de sementes de soja (Glycine max (L.) Merrill). 1996. $135 \mathrm{f}$. Tese (Doutorado em Fitotecnia) - Universidade Federal de Viçosa, Viçosa-MG, 1996.
BRACCINI, A. L. et al. Efeito do condicionamento osmótico na germinação e no vigor de sementes de soja.

R. Bras. Sementes, v. 19, n. 1, p. 71-79, 1997.

BRACCINI, A. L. et al. Avaliação da qualidade fisiológica de sementes de soja, após o processo de hidrataçãodesidratação e envelhecimento acelerado. Pesq. Agropec. Bras., v. 34, n. 6, p. 1053-1066, 1999.

BRADFORD, D. J. Manipulation of seed water relations via osmotic priming to improve germination under stress conditions. Hort. Sci., v. 21, p. 1105-1112, 1986.

BRASIL. Ministério da Agricultura e Reforma Agrária. Regras para análises de sementes. Brasília-DF: 1992. $365 \mathrm{p}$.

BRAY, C. M. Biochemical processes during the osmopriming of seeds. In: KIGEL, J.; GALILI, G. Seed development and germination. New York: Marcel Decker, 1995. p. 767-789.

CAMARGO, R. Condicionamento fisiológico de sementes de cafeeiro (Coffea arabica L.). 1998. 108 f. Dissertação (Mestrado em Fitotecnia) - Universidade Federal de Lavras, Lavras, 1998. 
DEL GIÚDICE, M. P. Condicionamento osmótico de sementes de soja (Glycine $\max$ (L.) Merrill). 1996. $130 \mathrm{f}$. Tese (Doutorado em Fitotecnia) - Universidade Federal de Viçosa, Viçosa-MG, 1996.

DEL GIÚDICE, M. P. et al. Efeito do condicionamento osmótico na germinação de sementes de dois cultivares de soja. Rev. Ceres, v. 46, n. 266, p. 435-444, 1999.

DURIGAN, J. C. et al. Períodos de matocompetição na cultura da soja (Glycine $\max$ (L.) Merrill), cultivares Santa Rosa e IAC-2. I - Efeitos sobre parâmetros de produção. II Efeitos sobre características morfológicas das plantas e constituição química dos grãos. Planta Daninha, v. 6, n. 2, p. 86-100, 111-114, 1983.

FLECK, N. G. Interferência de papuã (Brachiaria plantaginea) com soja e ganho de produtividade obtido através do seu controle. Pesq. Agrop. Gaúcha, v. 2, n. 1, p. 63-68, 1996.

HELSEL, D. G.; HELSEL, Z. R.; MINOR, H. C. Field studies on osmoconditioning soybeans. Field Crops Res., v. 14, p. 291-297, 1986.
HEYDECKER, W.; HIGGINS, J.; TURNER, Y. J.

Invigoration of seeds? Seed Sci. Technol., v. 3, p. 881-888, 1975.

KHAN, A. A. Preplant physiological seed conditioning. Hort. Rev., v. 3, p. 131-181, 1992.

LIMA, W. A. A. Condicionamento fisiológico, germinação e vigor de sementes de café (Coffea arabica L.). 1999. 117 f. Dissertação (Mestrado em Fitotecnia) Universidade Federal de Viçosa, Viçosa-MG, 1999.

MICHEL, B. E.; KAUFMANN, M. R. The osmotic potential of polyethylene glycol 6000. Plant Physiol., v. 51, p. $914-916,1973$.

RADOSEVICH, S.; HOLT, J.; GHERSA, C. Physiological aspects of competition. In: Weed Ecology Implications Manegements. New York: John Willey Sons, 1996. p. 217301 .

SPADOTTO, C. A. et al. Avaliação de parâmetros para o monitoramento da interferência de plantas daninhas na cultura de soja (Glycine max L.). Planta Daninha, v. 10, n. 1/2, p. 33-38, 1992. 